\title{
Response of Penaeid Prawns (Metapanaeus monoceros) to Textile Dye Industrial Effluents (TDIE): An Indicator of Stress
}

\author{
R. Praneeth Rahul ${ }^{1 *}$, P.V. Shirodkar ${ }^{1}$, R. Mani Murali ${ }^{1}$, J. Ravindran ${ }^{2}$, Satyanarayana Brahma ${ }^{3}$ and P. Vethamony \\ ${ }^{1}$ National Institute of Oceanography, Dona Paula, Goa 403 004, India \\ ${ }^{2}$ National Institute of Oceanography (CSIR), Regional Centre, Dr. Salim Ali Road, PB. No. 1913, Kochi-682018, India \\ ${ }^{3}$ Indira Gandhi Centre for Atomic Research, Kalpakkam 603 102, TN, India
}

\begin{abstract}
Studies on acute toxicity of textile effluents, collected from various Textile Dye Industries from Erode industrial area, Tamil Nadu, have been carried out. The juveniles of pink prawns (Metapanaeus monoceros) were exposed to a mixture of effluent samples in five different concentrations prepared in seawater, using static acute toxicity test protocol to obtain the $96-\mathrm{LC}_{50}$. The five different dilution factors of effluents made up with seawater were 200, 100, 50, 33.33, and 20 respectively. The environmental factors such as salinity, temperature, dissolved oxygen and $\mathrm{pH}$ were monitored from different effluent dilutions every 24 hours during the experiment till 96 hours. Each tank of different effluent dilution contained 10 test organisms in $3 \mathrm{~L}$ of effluent content besides a control tank. The results showed that the $96-\mathrm{LCC}_{50}$ of Erode effluent samples for prawns is $29 \mathrm{ppm}$, the upper limit is $41 \mathrm{ppm}$ and the lower limit is $17 \mathrm{ppm}$. Maximum mortalities occurred at a dilution factor 20 i.e. concentration of $50 \mathrm{ppm}$. This indicated a greater toxicity of these tested textile effluents from Erode (with a Dilution Factor of 20) as compared to the effluents tested earlier by other workers from different dye industries in Erode area (with a Dilution Factor of 5).
\end{abstract}

Keywords: Textile industries effluent; Erode; Acute toxicity; $\mathrm{LC}_{50}$; Penaeid prawns

\section{Introduction}

Erode district in Tamil Nadu, India is a rapidly growing city and is one of the well known center for textile industries. It has about 736 big textile dyeing units and several small dying units. All these dyeing units utilize large quantity of water for their process and generate huge quantity of wastewater or effluents [1], and the effluents are normally discharged in the adjacent riverine environments or in small streams in the Erode area. Such practice was going on over a period of last few decades and it has seriously affected the aquatic environment. The textile effluents are important sources of toxic substances, organic and inorganic in nature. Considering the gravity of situation of the ongoing environmental degradation in Erode, the Textile Ministry, Govt. of Tamil Nadu, with the support of the Department of Science and Technology (DST), New Delhi proposed to have a common effluent pipeline to discharge the effluents from all the textile dying industries from Erode directly into the coastal sea after treatment. Such a huge discharge of effluents can have a devastating effect on the coastal marine water quality and productivity [2]. The evaluation of toxicity of these effluents prior to discharge is therefore highly necessary for understanding the extent of its toxicity and the measures to be taken for reducing the toxicity before it is discharged into the sea. In order to understand the toxicity limit of a mixture of textile dye industrial effluent (TDIE), the effluents, particularly the RO (reverse osmosis) rejects were collected from each of the 9 selected dye industries in Erode area during May 2011 and after mixing in equal proportions were used for toxicity studies using static acute toxicity test. This unique study is maiden attempt to explore the toxicity of effluents when released in the marine environment of the east coast of India.

\section{Material and Method}

The TDIE or the RO rejects were collected from 9 textile industries from the Erode Industrial area. Part of these collected effluents was used for physico-chemical analyses at the site itself and the other part was taken to the National Institute of Oceanography laboratory at Goa for bioassays studies.
The parameters analyzed for physico-chemical studies of the effluents included $\mathrm{pH}$, turbidity, salinity, phosphate, nitrite, nitrate, ammonia, silicate, urea as per Strickland and Parsons, Grasshoff and APHA [3-5]. Total suspended solids (TSS) were measured by filtration using Filtration pump (Aspirator Vacuum). Millipore vacuum filter pump was used for the filtration and the samples were filtered through pre-weighed $0.45 \mu \mathrm{m}$ filter papers. TSS was calculated from the initial and final weights of the filter paper after filtration. The heavy metals in the effluents were analyzed using ICP-AES. Trace metals were analyzed by Ion chromatography (DIONEX ICS-2500), while the mercury was analyzed by Mercury analyzer, (BUCK Scientific 410 Mercury analyzer). The total organic carbon analyses were carried out using TOC analyzer (SHIMADZU TOC-VCPH).

For bioassay study, all the effluent samples were mixed together in equal proportion and a known quantity of the mixed sample was used for toxicity test after dilution. A known volume of sea water was measured using a measuring cylinder into a clean, dry bioassay tank and a pre determined volume of the mixed effluent was added to the sea water to make it up to $1000 \mathrm{ml}$ (total volume of test media) to achieve the desired test concentration. The toxicity test was done on prawns (Metapanaeus monoceros), using each of the diluted effluents having different dilutions of 200,100,50,33.33 and 20, along with a control with no effluent in it. The bioassay test used was the acute static non renewal toxicity test following Sridevi and Kanmani [6], to understand

*Corresponding author: R. Praneeth Rahul, National Institute of Oceanography, Dona Paula, Goa 403 004, India, Tel: 8125380609, E-mail: praneethrahulr@gmail.com

Received February 27, 2013; Accepted May 23, 2013; Published May 27, 2013

Citation: Praneeth Rahul R, Shirodkar PV, Mani Murali R, Ravindran J, Brahma S, et al. (2013) Response of Penaeid Prawns (Metapanaeus monoceros) to Textile Dye Industrial Effluents (TDIE): An Indicator of Stress. J Environ Anal Toxicol 3 : 175. doi:10.4172/2161-0525.1000175

Copyright: (C) 2013 Praneeth Rahul R, et al. This is an open-access article distributed under the terms of the Creative Commons Attribution License, which permits unrestricted use, distribution, and reproduction in any medium, provided the original author and source are credited. 
Citation: Praneeth Rahul R, Shirodkar PV, Mani Murali R, Ravindran J, Brahma S, et al. (2013) Response of Penaeid Prawns (Metapanaeus monoceros) to Textile Dye Industrial Effluents (TDIE): An Indicator of Stress. J Environ Anal Toxicol 3: 175. doi:10.4172/2161-0525.1000175

Page 2 of 9

the response of Penaeid prawns (Metapaeneus monoceros) to each of the diluted textile dye industrial effluent (TDIE) for evaluating toxicity.

\section{Test animal}

The Penaeid prawns, M. monoceros, an economically important crustacean species are harvested in considerable quantities from estuarine mangrove environments and traditional aquaculture ponds of Goa along the west coast of India, with riverine/estuarine environments [7]. This species is in great demand due to its high nutritional value and forms a cheap source of animal protein for lower and middle income groups. The prawns Metapanaeus monoceros (Arthropoda, Crustacean, Decapoda) of similar sizes ranging from 5 to $7 \mathrm{~cm}$ with a body weight of 1.5 to $2 \mathrm{~g}$ were utilized for the bioassay in this study. These prawns were regularly obtained from Britona, Goa and efforts were made to obtain the prawns from the same location throughout the experiment period to reduce variability in biotypes. These prawns were selected for the toxicity study because they are very sensitive to contaminants and show mortality at lethal concentrations.

The penaeid prawns were kept in a tank filled with $40 \mathrm{~L}$ water from the estuary and left for a minimum of 7 days to allow acclimatization of prawns to experimental conditions (Temp.: $28 \pm 1^{\circ} \mathrm{C}$; $\mathrm{pH} 7.98$ to 8.10 , Salinity: $\left.12 \pm 2 \%_{0}\right)$. During the period of acclimatization, the prawns were fed on the prepared fish meal ( $5 \%$ of the average body weight of total animals) (Table 1). The tank was continuously aerated with an air pump. Dead shrimps, if any, were immediately removed from the acclimatization tank. The $50 \%$ of water was changed daily to prevent the accumulation of waste metabolites and decaying food materials [8]. In order to reduce the excreted waste in the test tanks, the feeding was stopped $24 \mathrm{hrs}$ prior to the commencement of acute bioassay tests.

\section{Test method}

Short-term $\mathrm{LC}_{50}$ (median lethal concentration) toxicity tests were carried out according to the methods described by the APHA [5]. The prawns were sampled randomly from the holding tanks and transferred to the test and control solutions. The toxicity testing was done following the acute static non renewal method [6]. Toxicity testing is one of the common approaches for studying the impact of contaminant on marine organisms.

Tests are to be static tests. They should conform to the normal requirements of bioassay procedures and in particular, there should be:-

a) At least one control chamber and four test chambers each, having a different concentration of test effluent.

b) Full randomization of chamber and animals.

c) Test chambers are to be gently aerated to prevent stratification of test media. At least ten animals per test chamber but the biomass should not exceed one gram per liter and dissolved oxygen should not fall below $4 \mathrm{mg} / \mathrm{l}$ in $24 \mathrm{hrs}$.

These tests provide an initial hazard assessment. The toxicity of the contaminants was assessed using the routine acute static bioassay method based on the determination of $\mathrm{LC}_{50}$ values for 24, 48, 72 and 96hrs exposure period. The median lethal concentration (96-h $\mathrm{LC}_{50}$ ) and $95 \%$ confidence intervals were determined with a computerbased program described by Finney [9]. Test data were reported as the toxicity response curves showing the Lethal Time (LT) value against each concentration tested. The $96 \mathrm{hr} \mathrm{LC}{ }_{50}$ values were determined from the response curves.

\section{Assessment of quantal response (mortality)}

Prawns, $M$. monoceros, were assumed to be dead if there was no movement of the appendages, opercula, or mouth even when prodded with a blunt glass rod.

\section{Bioassay}

The prawns were exposed to effluent sample mixtures with varying dilution factors of 200,100,50,33.33, and 20, which corresponds to the concentrations of $5 \mathrm{ppm}, 10 \mathrm{ppm}, 20 \mathrm{ppm}, 30 \mathrm{ppm}$ and $50 \mathrm{ppm}$ respectively and an untreated control with no effluent. Mortality assessment was carried out once in every $24 \mathrm{~h}$ over a period of 4 days.

\section{Statistical analyses}

Toxicological dose-response data involving quantal response (mortality) studies were analyzed by probit analysis [9]. The indices of toxicity measurement derived from these analyses were $\mathrm{LC}_{50}$ (median lethal concentration that causes $50 \%$ response (mortality) of exposed organisms), $\mathrm{LC}_{95}$ (lethal concentration that causes 95\% response (mortality) of exposed organisms), $\mathrm{LC}_{05}$ (lethal concentration that causes $5 \%$ response (mortality) of exposed organisms) and TF (toxicity factor for relative potency measurements e.g., ratio of $96 \mathrm{~h} \mathrm{LC}_{50}$ of a compound to $\mathrm{LC}_{50}$ values at equivalent time intervals).

\section{Results and Discussion}

\section{Physico-chemical parameters}

The physico-chemical characteristics of the RO reject samples from the textile units showed that the ammonia and nitrate concentrations are very high, to the extent of $3048.94 \mu \mathrm{mol} / \mathrm{L}$ and $931.47 \mu \mathrm{mol} / \mathrm{L}$ respectively. Such high concentrations of ammonia and nitrate are found to act toxic to the central nervous system (CNS) of aquatic fishes, molluscs and crustaceans [10]. So, the higher concentrations of ammonia and nitrate present in the $\mathrm{RO}$ rejects can cause great damage to the aquatic life in the area if the reject is discharged in the sea.

Normally, the phosphate and nitrate are the two main nutrients responsible for biological productivity in the sea [11]. However, Chen et al. [12], during their experiments found that the ammonia is more toxic than nitrite, and nitrate is slightly toxic to shrimp. The median lethal concentrations $\left(\mathrm{LC}_{50}\right)$ of ammonia and nitrite have been estimated for penaeid shrimp post larvae, such as Penueus monodon, $P$. chinensis, $P$. puulensis. and $P$. juponicus by many workers viz. Chin and Chen, Chen and Chin, Chen and Lin [13-15,]. They showed that ammonia causes damage to their central nervous system. In case of penaeid shrimps, the presence of high concentrations of ammonia in the environment may affect their acid-base balance, haemolymph, osmolarity, nitrogen metabolism, respiration, and growth rates and may also enhance molting [16]. Studies on the effect of nitrite on freshwater animals by Lewis and Morris [17], indicated the inducement of reversible methaemoglobin formation, which is an inablity to transport oxygen to the tissues [10].

Besides nutrients, very high levels of TDS upto $39,000 \mathrm{mg} / \mathrm{L}$ also have been observed in these RO reject samples. Boyd and Claude [18], have shown that most of the aquatic ecosystems involving mixed fish fauna can tolerate TDS levels of upto $1000 \mathrm{mg} / \mathrm{L}$. Comparatively, the observed high TDS (av.19617.3 mg/l) in Erode effluent mixture can have a a significant negative effect on fisheries of the region.

\section{Wet effluent toxicity test}

The $\mathrm{LD}_{50}$ represents a dose that would kill half of the population that 
is exposed to it. "WET" is a term used to describe the adverse effects or toxicity to a population of aquatic organisms caused by exposure to an effluent. This toxicity is experimentally determined in the laboratory by exposing sensitive organisms (usually surrogate organisms representative of those found in the environment) to effluents using WET tests. Responses assessed usually include survival, growth, and/or reproduction. WET testing is used to assess and regulate the combined effects of all the constituents of a complex effluent rather than the conventional methods of controlling the toxicity of single chemical or constituent. Whole effluent toxicity (WET) tests can be more realistic than the study of individual pollutants and are recognized as practical and effective tools for the assessment of combined effects of toxic substances on aquatic ecosystems. Though WET tests do not provide indication of the specific cause(s) of toxicity, they contribute to overall effects that a mixture of pollutants might produce on the aquatic environment [19]. In order to know the level of toxicity of RO reject samples mixture to the aquatic life, the prawns were exposed to a mixture of effluent samples diluted to varying concentrations (dilution factors of 200, 100, 50, 33.33, and 20). Prior to the exposure of prawns, they were found to be active but after exposure to the industrial effluent mixtures of varying concentrations, their activity started showing an increase as seen from their agitated swimming. Thereafter, the activity showed a gradual reduction with a loss of equilibrium, progressive weakness and periods of inactivity and quiescence. Eventually, the organisms showed mortality, and this was confirmed when there was no response to gentle prodding to a blunt pair of forceps. Following the death, the exoskeleton of the prawns turned whitish from their original transparent color. The intensity of these symptoms was directly related to the concentration of effluent as well as the duration of exposure. As seen from Figure 1, a zero percent mortality was observed in effluent with 200 dilution factor, whereas $70 \%$ mortality was observed in effluent with 20 dilution factor after 96 hours period.

This showed that as the dilution factor increases the mortality percent decreases. In toxicity studies carried out by Sridevi and Kanmani [6], a higher mortality rate was observed in an effluent with a dilution factor of 5 using ionized textile dyeing industries waste water. The present study carried out on the toxicity evaluation of RO reject effluents from Erode textile industries showed that the toxicity levels are not meeting the standards as recommended by the MINAS (Minimum National Standards as proposed by the Central Pollution Control Board involving three other laboratories i.e. Gujarat Pollution Control Board, Gandhinagar; National Institute of Occupational Health (NIOH), Ahmedabad and National Environmental Engineering Research Institute, Nagpur) for dye and dye intermediate industries. MINAS has recommended a toxicity factor of 4.0 (Dilution factor 4) for treated effluents from dye and dye intermediate industries. This implies that the treated industrial effluent should not show acute toxicity for fish, if diluted four times. Comparatively, our observations show that the toxicity of the mixture of effluent samples from Erode is high, suggesting that they are more toxic even at a dilution factor of 20 . This is also higher as compared to the toxicity test done by Sridevi and Kanmani [6], using effluents from other textile dying industrial units in Erode area.

The $\mathrm{RO}$ reject samples from all the stations were made into one mixture and the dilutions were made by using seawater and a control without the effluent. To express the lethal concentration of the effluents with dilution factors of $200,100,50,33.33,20$, the dilution factors were converted to ppm. The penaeid prawns were kept in the tanks containing effluents with different dilution factors after the acclimatization period. It was observed that after 24 hours there was no mortality in all the concentrations. This indicated that there was no effect on the penaeid prawns for the dilution factors of 200, 100, 50, 33.33 and 20 for an exposure period of 24 hours (Table 2). Thereafter, at 48 hours, the observations showed $10 \%$ mortality in both the effluents with 33.33 and 20 dilution factors. Rest of the diluted effluents showed zero mortality after 48 hours (Table 3). Then, after 72 hours there was an increase in mortality from $10 \%$ to $40 \%$ in both the effluents with dilution factors of 33.33 and $20.30 \%$ mortality was observed in effluent with 50 dilution factors and $10 \%$ mortality was observed in effluent with 100 dilution factor whereas, no mortality was observed in effluent with 200 dilution factor (Table 4). After 96 hours, 70\% mortality was observed in effluent with 20 dilution factor; $60 \%$ mortality in 33.33 dilution factor; $50 \%$ mortality in 50 dilution factor and $20 \%$ mortality in 100 dilution factor (Table 5). Throughout the experiment there was no mortality observed in the control tank and in the effluent with 200 dilution factor. This clearly indicates that as the dilution factor decreases, the mortality of prawns' increases with time. The effluent with a Dilution Factor of 200 can be considered as No Observable Effect Level (NOEL) as there was no mortality observed in prawns even after 96 hours of exposure.

\section{Probit analysis}

Probit Analysis is a method of analyzing the relationship between a stimulus (dose) and the quantal (all or nothing) response. In a typical quantal response experiment, groups of animals are given different doses of an effluent or a chemical and the percent dying at each dose level is recorded and the data analyzed using Probit Analysis.

The effect of any substance depends on a number of factors. The most important factor is the dose-time relationship (Table 6). The dose-time relationship indicates the quantity of substance involved and how often the exposure to the substance has occurred. This relationship gives rise to two different types of toxicity studies, and they are acute and chronic toxicity studies.

The Probit model assumes that the percent response is related to the logarithmic dose as the cumulative normal distribution. That is, the log doses may be used as variables to read the percent dying from the cumulative normal (Table 7). Using the normal distribution, rather

96 HOURS

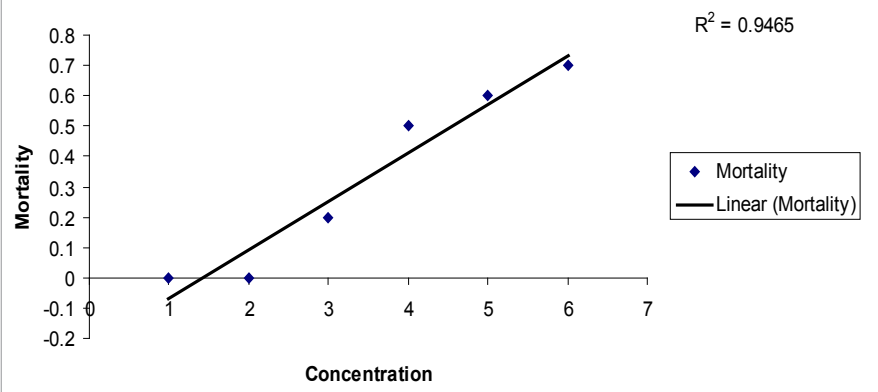

Figure 1: 98 Hours Mortality.

\begin{tabular}{|c|c|}
\hline Mean wet weight $\mathbf{( g )}$ & Daily feeding rate (\% of body weight) \\
\hline$<5$ & 0 \\
\hline $5-15$ & 7 \\
\hline $15-25$ & 5 \\
\hline$>25$ & 3 \\
\hline
\end{tabular}

As fed weight of diet/wet biomass of prawns $\times 100$

Table 1: Weight dependent feeding rates of $M$.monoceros. 
Citation: Praneeth Rahul R, Shirodkar PV, Mani Murali R, Ravindran J, Brahma S, et al. (2013) Response of Penaeid Prawns (Metapanaeus monoceros) to Textile Dye Industrial Effluents (TDIE): An Indicator of Stress. J Environ Anal Toxicol 3: 175. doi:10.4172/2161-0525.1000175

Page 4 of 9

\begin{tabular}{|c|c|c|c|c|c|}
\hline Sr. No. & Dilution Factor & Concentration (ppm) & Total animals & Mortality & 0 \\
\hline 1 & 0 & 0 & 10 & 0 \\
\hline 2 & 200 & 5 & 10 & 0 \\
\hline 3 & 100 & 10 & 10 & 0 \\
\hline 4 & 50 & 20 & 10 & 0 \\
\hline 5 & 33.33 & 30 & 10 & 0 \\
\hline 6 & 20 & 50 & 10 & $0 \%$ \\
0 & $0 \%$ & 0 \\
\hline
\end{tabular}

After 24 hours exposure to the five different concentrations of the effluent sample there was no mortality observed

Table 2: 24 Hours Mortality.

\begin{tabular}{|c|c|c|c|c|c|}
\hline Sr. No. & Dilution Factor & Concentration (ppm) & Total animals & Mortality & 0 \\
\hline 1 & 0 & 0 & 10 & 0 \\
\hline 2 & 200 & 5 & 10 & 0 \\
\hline 3 & 100 & 10 & 10 & 0 \\
\hline 4 & 50 & 20 & 10 & 0 \\
\hline 5 & 33.33 & 30 & 10 & 0 \\
\hline 6 & 20 & 50 & 10 & 1 \\
\hline
\end{tabular}

After 48 hours exposure period it was observed that there is $10 \%$ mortality in $30 \mathrm{ppm}$ and $50 \mathrm{ppm}$ concentrations of effluent sample

Table 3: 48 Hours Mortality.

\begin{tabular}{|c|c|c|c|c|c|}
\hline Sr. No. & Dilution Factor & Concentration (ppm) & Total animals & Mortality & 0 \\
\hline 1 & 0 & 0 & 10 & 0 \\
\hline 2 & 200 & 5 & 10 & 0 \\
\hline 3 & 100 & 10 & 10 & 1 \\
\hline 4 & 50 & 20 & 10 & 3 \\
\hline 5 & 33.33 & 30 & 10 & 4 \\
\hline 6 & 20 & 50 & 10 & $40 \%$ \\
\hline
\end{tabular}

After 72 hours exposure period it was observed that in $10 \mathrm{ppm}$ concentration of effluent there was $10 \%$ mortality, for $20 \mathrm{ppm}$ there was $30 \%$ mortality, $30 \mathrm{ppm}$ there was 40 $\%$ mortality and for $50 \mathrm{ppm}$ there was $40 \%$ mortality observed

Table 4: 72 Hours Mortality

\begin{tabular}{|c|c|c|c|c|c|}
\hline Sr. No. & Dilution Factor & Concentration (ppm) & Total animals & Mortality & 0 \\
\hline 1 & 0 & 0 & 10 & 0 \\
\hline 2 & 200 & 5 & 10 & $0 \%$ \\
\hline 3 & 100 & 10 & 10 & 2 \\
\hline 4 & 50 & 20 & 10 & 5 \\
\hline 5 & 33.33 & 30 & 10 & 6 \\
\hline 6 & 20 & 50 & 10 & $50 \%$ \\
7
\end{tabular}

After 96 hours exposure to the effluent sample, in 10ppm concentration there was $20 \%$ mortality, in $20 \mathrm{ppm}$ there was $50 \%$ mortality, in $30 \mathrm{ppm}$ concentration there was $60 \%$ mortality and in 50ppm concentration there was $70 \%$ mortality

Table 5: 96 Hours Mortality.

\begin{tabular}{|c|c|c|c|c|c|}
\hline \multirow[b]{2}{*}{ Dilution Factor } & \multirow[b]{2}{*}{ Concentration (ppm) } & \multicolumn{4}{|c|}{ Percentage Mortality } \\
\hline & & 24 hours & 48 hours & 72 hours & 96 hours \\
\hline 0 & 0 & 0 & 0 & 0 & 0 \\
\hline 200 & 5 & 0 & 0 & 0 & 0 \\
\hline 100 & 10 & 0 & 0 & 10 & 20 \\
\hline 50 & 20 & 0 & 0 & 30 & 50 \\
\hline 33.33 & 30 & 0 & 10 & 40 & 60 \\
\hline 20 & 50 & 0 & 10 & 40 & 70 \\
\hline
\end{tabular}

Table 6: Percentage mortality for $24 \mathrm{hrs}, 48 \mathrm{hrs}, 72 \mathrm{hrs}$, and $96 \mathrm{hrs}$ for effluent.

than other probability distributions, influences the predicted response rate at the high and low ends of possible doses, but has little influence near the middle. Hence, much of the comparison of different drugs is done using response rates of fifty percent. The probit model may be expressed mathematically as follows: $P=\alpha+\beta\left[\log _{10}\right.$ (Dose) $]$

Where, $\mathrm{P}$ is five plus the inverse normal transform of the response rate (called the Probit). The five is added to reduce the possibility of negative probits, a situation that caused confusion when solving the problem by hand. When using Finney method, the regression line is created for logs of doses. Some programs in Finney method adjust 0 $\%$ and $100 \%$ lethality under the formula $49 \% / \mathrm{N}$, instead of $25 \% / \mathrm{N}$.

The median lethal concentration $\left(96-\mathrm{h} \mathrm{LC}_{50}\right)$ and $95 \%$ confidence intervals were determined as described by Finney [9]. As there was no mortality observed after 24 hours, it is considered as a zero value 
Citation: Praneeth Rahul R, Shirodkar PV, Mani Murali R, Ravindran J, Brahma S, et al. (2013) Response of Penaeid Prawns (Metapanaeus monoceros) to Textile Dye Industrial Effluents (TDIE): An Indicator of Stress. J Environ Anal Toxicol 3: 175. doi:10.4172/2161-0525.1000175

Page 5 of 9

for the $\mathrm{LC}_{50}$. Then after 48 hours the $\mathrm{LC}_{50}$ was observed as $119.6 \mathrm{ppm}$ with $158.52 \mathrm{ppm}$ as the upper limit and $80.7 \mathrm{ppm}$ as the lower limit (Table 8 and Figure 2). The intercept for 48 hours LC $_{50}$ value is 2.9629 and Chi square value is 31.839 Figure1. After 72 hours, the $\mathrm{LC}_{50}$ value is $51 \mathrm{ppm}$ with $68.69 \mathrm{ppm}$ as the upper limit and $33.3 \mathrm{ppm}$ as the lower limit (Table 9 and Figure 3).. The intercept for 72 hours, the $\mathrm{LC}_{50}$ value is 3.6959 and the Chi square value is 0.5366 . After 96 hours exposure period, the $\mathrm{LC}_{50}$ value was $29.17 \mathrm{ppm}$ with an upper limit of $41.4 \mathrm{ppm}$ and the lower limit of $16.9 \mathrm{ppm}$ Figure 3. The intercept for 96 hours $\mathrm{LC}_{50}$ value is 3.9211 and Chi square value is 0.4088 (Table 10 and Figure 4). The 96-h $\mathrm{LC}_{50}$ values for other shrimp species ranged between 23.7 ppm for P. semisulcatus and $70.9 \mathrm{ppm}$ for P. monodon [12].

\section{Conclusion}

In the present study, the effluent samples (RO rejects) were obtained from 9 dye industries located at Erode in Tamil Nadu and used for toxicity testing of prawns (Metapenaeus monoceros) collected from off Britona, Goa. All the 9 effluents were mixed together and a mixture of the effluents from Erode textile dye industries was subsequently diluted further with different dilution factors of $200,100,50,33.33$ and 20 and exposed to prawns along with a control with no effluent for evaluating toxicity. Penaeid prawns (Metapaeneus monoceros) are widely distributed in different size groups. They are commercially important cultivable species and have high export demand in India. This species was used for acute toxicity testing because of their large availability, sensitivity and relative ease of handling.

The experiment showed that the Lethal Concentration for killing $50 \%$ organisms $\left(\mathrm{LC}_{50}\right)$ increases with a decrease in dilution and an increase in time. A high mortality (70\%) was observed in effluent

\begin{tabular}{|c|c|c|c|c|c|}
\hline Exposure period & LC $_{\mathbf{5 0}}$ & Upper Limit & Lower Limit & Intercept & Chi square \\
\hline $\mathbf{2 4} \mathbf{~ h}$ & - & - & - & - & - \\
\hline $\mathbf{4 8} \mathbf{~ h}$ & $119.6 \mathrm{ppm}$ & $158.52 \mathrm{ppm}$ & $80.7 \mathrm{ppm}$ & 2.9629 & 31.839 \\
\hline $\mathbf{7 2} \mathbf{~ h}$ & $51 \mathrm{ppm}$ & $68.69 \mathrm{ppm}$ & $33.3 \mathrm{ppm}$ & 3.6959 & 0.5366 \\
\hline $\mathbf{9 6} \mathbf{~ h}$ & $29.17 \mathrm{ppm}$ & $41.40 \mathrm{ppm}$ & $16.9 \mathrm{ppm}$ & 3.9211 & 0.4088 \\
\hline
\end{tabular}

Table 7: Median Lethal concentration ( $\left(\mathrm{CC}_{50}\right)$ (with $95 \%$ confidence intervals) for TDIE.

\begin{tabular}{|c|c|c|c|c|c|c|c|}
\hline $\begin{array}{l}\text { Alpha value (for confidence } \\
\text { interval) }\end{array}$ & 0.05 & & & & & & \\
\hline \multicolumn{8}{|c|}{ Probit Analysis - Finney Method [Lognormal Distribution] } \\
\hline Log10[Dose (Stimulus)] & Actual Percent (\%) & Probit Percent(\%) & $\mathbf{N}$ & $\mathbf{R}$ & $E(R)$ & Difference & Chi-square \\
\hline 0.699 & 0.025 & 0.0002 & 10 & 0.25 & 0.0021 & 0.2479 & 29.2063 \\
\hline 1. & 0.025 & 0.0025 & 10 & 0.25 & 0.0253 & 0.2247 & 2. \\
\hline 1.301 & 0.025 & 0.0187 & 10 & 0.25 & 0.1873 & 0.0627 & 0.021 \\
\hline 1.4771 & 0.1 & 0.0487 & 10 & 1. & 0.4867 & 0.5133 & 0.5414 \\
\hline 1.699 & 0.1 & 0.1303 & 10 & 1. & 1.3027 & -0.3027 & 0.0704 \\
\hline \multicolumn{8}{|l|}{ Chi-square } \\
\hline Chi-square & 31.839 & & & & & & \\
\hline Degrees Of Freedom & 3 & & & & & & \\
\hline p-level & 0. & & & & & & \\
\hline \multicolumn{8}{|c|}{ Dose (Stimulus) Percentile } \\
\hline Percentile & Probit (Y) & Log10[Dose (Stimulus)] & Standard Error & Dose (Stimulus) & Standard Error & & \\
\hline 1 & 2.6732 & 1.1986 & -0.1425 & 15.7981 & -5.2755 & & \\
\hline 5 & 3.3548 & 1.4824 & -0.1189 & 30.3671 & -8.4199 & & \\
\hline 10 & 3.7183 & 1.6338 & -0.1149 & 43.028 & -11.5156 & & \\
\hline 16 & 4.0056 & 1.7534 & -0.0543 & 56.6736 & -7.1028 & & \\
\hline 20 & 4.1585 & 1.8171 & -0.077 & 65.6256 & -11.7017 & & \\
\hline 25 & 4.3258 & 1.8867 & -0.1355 & 77.0408 & -24.4347 & & \\
\hline 30 & 4.476 & 1.9493 & -0.1788 & 88.9726 & -37.6666 & & \\
\hline 40 & 4.7471 & 2.0621 & -0.2496 & 115.3785 & -70.015 & & \\
\hline 50 & 5. & 2.1674 & -0.312 & 147.0423 & -114.9488 & & \\
\hline 60 & 5.2529 & 2.2728 & -0.3727 & 187.3957 & -181.2693 & & \\
\hline 70 & 5.524 & 2.3856 & -0.4366 & 243.0123 & -287.5766 & & \\
\hline 75 & 5.6742 & 2.4482 & -0.4717 & 280.6493 & -368.3851 & & \\
\hline 80 & 5.8415 & 2.5178 & -0.5106 & 329.4667 & -482.9594 & & \\
\hline 84 & 5.9944 & 2.5815 & -0.546 & 381.508 & -616.3926 & & \\
\hline 90 & 6.2817 & 2.7011 & -0.6123 & 502.4973 & -967.5551 & & \\
\hline 95 & 6.6452 & 2.8525 & -0.6957 & 712.0034 & $-1,694.882$ & & \\
\hline 99 & 7.3268 & 3.1363 & -0.8513 & $1,368.6063$ & $-4,763.158$ & & \\
\hline \multicolumn{8}{|l|}{ Regression Statistics } \\
\hline LC50 & 147.0423 & LC50 Standard Error & 221.9314 & & & & \\
\hline$L C 50 L C L$ & 13.9977 & LC50 UCL & $1,544.6442$ & & & & \\
\hline $\log 10[L C 50]$ & 2.1674 & Standard Error & 0.5211 & & & & \\
\hline Beta & 2.4016 & Intercept & -0.2054 & & & & \\
\hline Beta Standard Error & 1.9318 & & & & & & \\
\hline
\end{tabular}


Citation: Praneeth Rahul R, Shirodkar PV, Mani Murali R, Ravindran J, Brahma S, et al. (2013) Response of Penaeid Prawns (Metapanaeus monoceros) to Textile Dye Industrial Effluents (TDIE): An Indicator of Stress. J Environ Anal Toxicol 3: 175. doi:10.4172/2161-0525.1000175

Page 6 of 9

\begin{tabular}{|c|c|c|c|c|}
\hline & \multicolumn{2}{|c|}{ Probit Analysis - Least squares [Normal Distribution] } & Probit (Y) & Weight (Z) \\
\hline Dose (Stimulus) & Actual Percent (\%) & N & 3.0396 & 1.0792 \\
\hline 5. & 0.025 & 10. & 3.0396 & 1.0792 \\
\hline 10. & 0.025 & 10. & 3.0396 & 1.0792 \\
\hline 20. & 0.025 & 10. & 3.7183 & 2.6548 \\
\hline 30. & 0.1 & 10. & \\
\hline 50. & 0.1 & 10. & 18.573 \\
\hline Regression Statistics & & & 158.5206 \\
\hline LC50 & $\mathbf{1 1 9 . 6 4 6 6}$ & LC50 Standard Error & 2.9629 \\
\hline LC50 LCL & 80.7726 & LC50 UCL & \\
\hline Beta & 0.017 & Intercept & \\
\hline Beta Standard Error & 0.021 & & 60.9132 \\
\hline
\end{tabular}

Table 8: 48 Hours Probit analysis.

\begin{tabular}{|c|c|c|c|c|c|c|c|}
\hline $\begin{array}{l}\text { Alpha value (for confidence } \\
\text { interval) }\end{array}$ & 0.05 & & & & & & \\
\hline \multicolumn{8}{|c|}{ Probit Analysis - Finney Method [Lognormal Distribution] } \\
\hline Log10[Dose (Stimulus)] & Actual Percent (\%) & \begin{tabular}{|l|l} 
Probit Percent (\%) \\
\end{tabular} & \begin{tabular}{l|l}
$\mathbf{N}$ & \\
\end{tabular} & $\mathbf{R}$ & $E(R)$ & Difference & Chi-square \\
\hline 0.699 & 0.025 & 0.0321 & 10 & 0.25 & 0.3213 & -0.0713 & 0.0158 \\
\hline 1. & 0.1 & 0.0975 & 10 & 1. & 0.9745 & 0.0255 & 0.0007 \\
\hline 1.301 & 0.3 & 0.229 & 10 & 3. & 2.2904 & 0.7096 & 0.2199 \\
\hline 1.4771 & 0.4 & 0.338 & 10 & 4. & 3.3803 & 0.6197 & 0.1136 \\
\hline 1.699 & 0.4 & 0.4962 & 10 & 4. & 4.9624 & -0.9624 & 0.1866 \\
\hline \multicolumn{8}{|l|}{ Chi-square } \\
\hline Chi-square & 0.5366 & & & & & & \\
\hline Degrees Of Freedom & 3 & & & & & & \\
\hline$p$-level & 0.9108 & & & & & & \\
\hline & & & & & & & \\
\hline \multicolumn{8}{|c|}{ Dose (Stimulus) Percentile } \\
\hline Percentile & Probit (Y) & $\begin{array}{c}\text { Log10 } \\
\text { [Dose (Stimulus)] }\end{array}$ & Standard Error & Dose (Stimulus) & Standard Error & & \\
\hline 1 & 2.6732 & 0.4402 & 0.846 & 2.7554 & 9.467 & & \\
\hline 5 & 3.3548 & 0.8104 & 0.5278 & 6.4628 & 9.9367 & & \\
\hline 10 & 3.7183 & 1.0079 & 0.3665 & 10.1826 & 9.6507 & & \\
\hline 16 & 4.0056 & 1.1639 & 0.253 & 14.5856 & 8.9852 & & \\
\hline 20 & 4.1585 & 1.247 & 0.2057 & 17.661 & 8.6796 & & \\
\hline 25 & 4.3258 & 1.3379 & 0.1763 & 21.7707 & 9.0829 & & \\
\hline 30 & 4.476 & 1.4195 & 0.1793 & 26.2697 & 11.1588 & & \\
\hline 40 & 4.7471 & 1.5667 & 0.2466 & 36.8721 & 22.0777 & & \\
\hline 50 & 5. & 1.7041 & 0.3442 & 50.593 & 44.4362 & & \\
\hline 60 & 5.2529 & 1.8415 & 0.454 & 69.4197 & 86.5293 & & \\
\hline 70 & 5.524 & 1.9887 & 0.5773 & 97.4375 & 171.1597 & & \\
\hline 75 & 5.6742 & 2.0703 & 0.6469 & 117.5729 & 247.443 & & \\
\hline 80 & 5.8415 & 2.1612 & 0.7251 & 144.9327 & 371.1382 & & \\
\hline 84 & 5.9944 & 2.2443 & 0.7971 & 175.4917 & 535.9255 & & \\
\hline 90 & 6.2817 & 2.4003 & 0.9331 & 251.3742 & $1,062.8553$ & & \\
\hline 95 & 6.6452 & 2.5978 & 1.1063 & 396.062 & $2,513.8633$ & & \\
\hline 99 & 7.3268 & 2.968 & 1.4327 & 928.9484 & $12,560.913$ & & \\
\hline \multicolumn{8}{|l|}{ Regression Statistics } \\
\hline LC50 & 50.593 & LC50 Standard Error & 44.4362 & & & & \\
\hline$\angle C 50 L C L$ & 29.3901 & LC50 UCL & 657.1199 & & & & \\
\hline Log10[LC50] & 1.7041 & Standard Error & 0.3442 & & & & \\
\hline Beta & 1.841 & Intercept & 1.8628 & & & & \\
\hline Beta Standard Error & 0.7079 & & & & & & \\
\hline
\end{tabular}


Citation: Praneeth Rahul R, Shirodkar PV, Mani Murali R, Ravindran J, Brahma S, et al. (2013) Response of Penaeid Prawns (Metapanaeus monoceros) to Textile Dye Industrial Effluents (TDIE): An Indicator of Stress. J Environ Anal Toxicol 3: 175. doi:10.4172/2161-0525.1000175

Page 7 of 9

\begin{tabular}{|c|c|c|c|c|}
\hline \multicolumn{5}{|c|}{ Probit Analysis - Least squares [Normal Distribution] } \\
\hline Dose (Stimulus) & Actual Percent (\%) & $\mathbf{N}$ & Probit (Y) & Weight (Z) \\
\hline 5. & 0.025 & 10. & 3.0396 & 1.0792 \\
\hline 10. & 0.025 & 10. & 3.0396 & 1.0792 \\
\hline 20. & 0.025 & 10. & 3.0396 & 1.0792 \\
\hline 30. & 0.1 & 10. & 3.7183 & 2.6548 \\
\hline 50. & 0.1 & 10. & 3.7183 & 2.6548 \\
\hline \multicolumn{5}{|l|}{ Regression Statistics } \\
\hline LC50 & 119.6466 & LC50 Standard Error & 18.5731 & \\
\hline LC50 LCL & 80.7726 & LC50 UCL & 158.5206 & \\
\hline Beta & 0.017 & Intercept & 2.9629 & \\
\hline Beta Standard Error & 0.021 & & & \\
\hline LC10 & 44.3663 & LC16 & 60.9132 & \\
\hline LC84 & 178.38 & LC90 & 194.9269 & \\
\hline LC100 & 207.7467 & & & \\
\hline
\end{tabular}

Table 9: 72 Hours Probit analysis

\begin{tabular}{|c|c|c|c|c|c|c|c|}
\hline $\begin{array}{l}\text { Alpha value (for confidence } \\
\text { interval) }\end{array}$ & 0.05 & & & & & & \\
\hline \multicolumn{8}{|c|}{ Probit Analysis - Finney Method [Lognormal Distribution] } \\
\hline Log10[Dose (Stimulus)] & Actual Percent (\%) & Probit Percent(\%) & $\mathbf{N}$ & $\mathbf{R}$ & $E(R)$ & Difference & Chi-square \\
\hline 0.699 & 0.025 & 0.0457 & 10 & 0.25 & 0.4572 & -0.2072 & 0.0939 \\
\hline 1. & 0.2 & 0.1698 & 10 & 2. & 1.6978 & 0.3022 & 0.0538 \\
\hline 1.301 & 0.5 & 0.4121 & 10 & 5. & 4.1206 & 0.8794 & 0.1877 \\
\hline 1.4771 & 0.6 & 0.5818 & 10 & 6. & 5.8177 & 0.1823 & 0.0057 \\
\hline 1.699 & 0.7 & 0.7723 & 10 & 7. & 7.7231 & -0.7231 & 0.0677 \\
\hline \multicolumn{8}{|l|}{ Chi-square } \\
\hline Chi-square & 0.4088 & & & & & & \\
\hline Degrees Of Freedom & 3 & & & & & & \\
\hline p-level & 0.9384 & & & & & & \\
\hline \multicolumn{8}{|c|}{ Dose (Stimulus) Percentile } \\
\hline Percentile & Probit (Y) & Log10[Dose (Stimulus)] & Standard Error & Dose (Stimulus) & Standard Error & & \\
\hline 1 & 2.6732 & 0.4365 & 0.3647 & 2.7321 & 2.5733 & & \\
\hline 5 & 3.3548 & 0.7165 & 0.2598 & 5.2058 & 3.3028 & & \\
\hline 10 & 3.7183 & 0.8658 & 0.2064 & 7.3418 & 3.6217 & & \\
\hline 16 & 4.0056 & 0.9838 & 0.1669 & 9.6344 & 3.7953 & & \\
\hline 20 & 4.1585 & 1.0467 & 0.1477 & 11.1343 & 3.8598 & & \\
\hline 25 & 4.3258 & 1.1154 & 0.1289 & 13.0429 & 3.9269 & & \\
\hline 30 & 4.476 & 1.1771 & 0.1148 & 15.0339 & 4.0221 & & \\
\hline 40 & 4.7471 & 1.2884 & 0.1002 & 19.4278 & 4.5237 & & \\
\hline 50 & 5. & 1.3923 & 0.1031 & 24.679 & 5.911 & & \\
\hline 60 & 5.2529 & 1.4962 & 0.1207 & 31.3495 & 8.8278 & & \\
\hline 70 & 5.524 & 1.6076 & 0.1502 & 40.512 & 14.2968 & & \\
\hline 75 & 5.6742 & 1.6693 & 0.1693 & 46.6961 & 18.6737 & & \\
\hline 80 & 5.8415 & 1.738 & 0.192 & 54.7007 & 24.9853 & & \\
\hline 84 & 5.9944 & 1.8008 & 0.2137 & 63.2164 & 32.3819 & & \\
\hline 90 & 6.2817 & 1.9189 & 0.256 & 82.9571 & 51.7879 & & \\
\hline 95 & 6.6452 & 2.0682 & 0.3114 & 116.9958 & 91.2509 & & \\
\hline 99 & 7.3268 & 2.3482 & 0.4179 & 222.9238 & 249.1922 & & \\
\hline \multicolumn{8}{|l|}{ Regression Statistics } \\
\hline LC50 & 24.679 & LC50 Standard Error & 5.911 & & & & \\
\hline$L C 50 L C L$ & 16.5872 & LC50 UCL & 42.0465 & & & & \\
\hline $\log 10[L C 50]$ & 1.3923 & Standard Error & 0.1031 & & & & \\
\hline Beta & 2.4343 & Intercept & 1.6106 & & & & \\
\hline Beta Standard Error & 0.6772 & & & & & & \\
\hline
\end{tabular}


Citation: Praneeth Rahul R, Shirodkar PV, Mani Murali R, Ravindran J, Brahma S, et al. (2013) Response of Penaeid Prawns (Metapanaeus monoceros) to Textile Dye Industrial Effluents (TDIE): An Indicator of Stress. J Environ Anal Toxicol 3: 175. doi:10.4172/2161-0525.1000175

Page 8 of 9

\begin{tabular}{|c|c|c|c|c|}
\hline \multicolumn{5}{|c|}{ Probit Analysis - Least squares [Normal Distribution] } \\
\hline Dose (Stimulus) & Actual Percent (\%) & $\mathbf{N}$ & Probit (Y) & Weight (Z) \\
\hline 5. & 0.025 & 10. & 3.0396 & 1.0792 \\
\hline 10. & 0.2 & 10. & 4.1585 & 3.8171 \\
\hline 20. & 0.5 & 10. & 5. & 5. \\
\hline 30. & 0.6 & 10. & 5.2529 & 4.7471 \\
\hline 50. & 0.7 & 10. & 5.524 & 4.452 \\
\hline \multicolumn{5}{|l|}{ Regression Statistics } \\
\hline LC50 & 29.1742 & LC50 Standard Error & 6.0467 & \\
\hline$L C 50 L C L$ & 16.9437 & LC50 UCL & 41.4048 & \\
\hline Beta & 0.037 & Intercept & 3.9211 & \\
\hline Beta Standard Error & 0.0153 & & & \\
\hline LC10 & -5.4857 & LC16 & 2.1327 & \\
\hline LC84 & 56.2158 & LC90 & 63.8341 & \\
\hline LC100 & 69.7365 & & & \\
\hline
\end{tabular}

Table 10: 96 Hours Probit analysis.

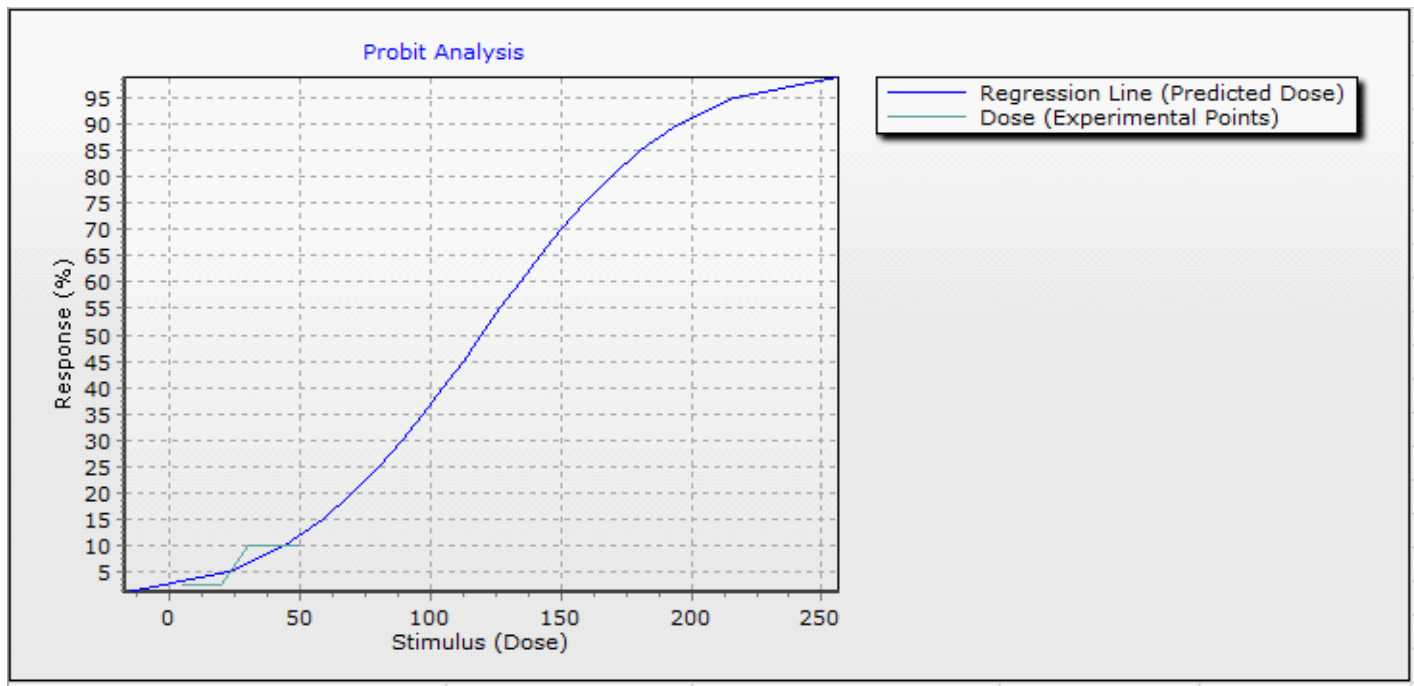

Figure 2: 48 Hours Probit analysis.
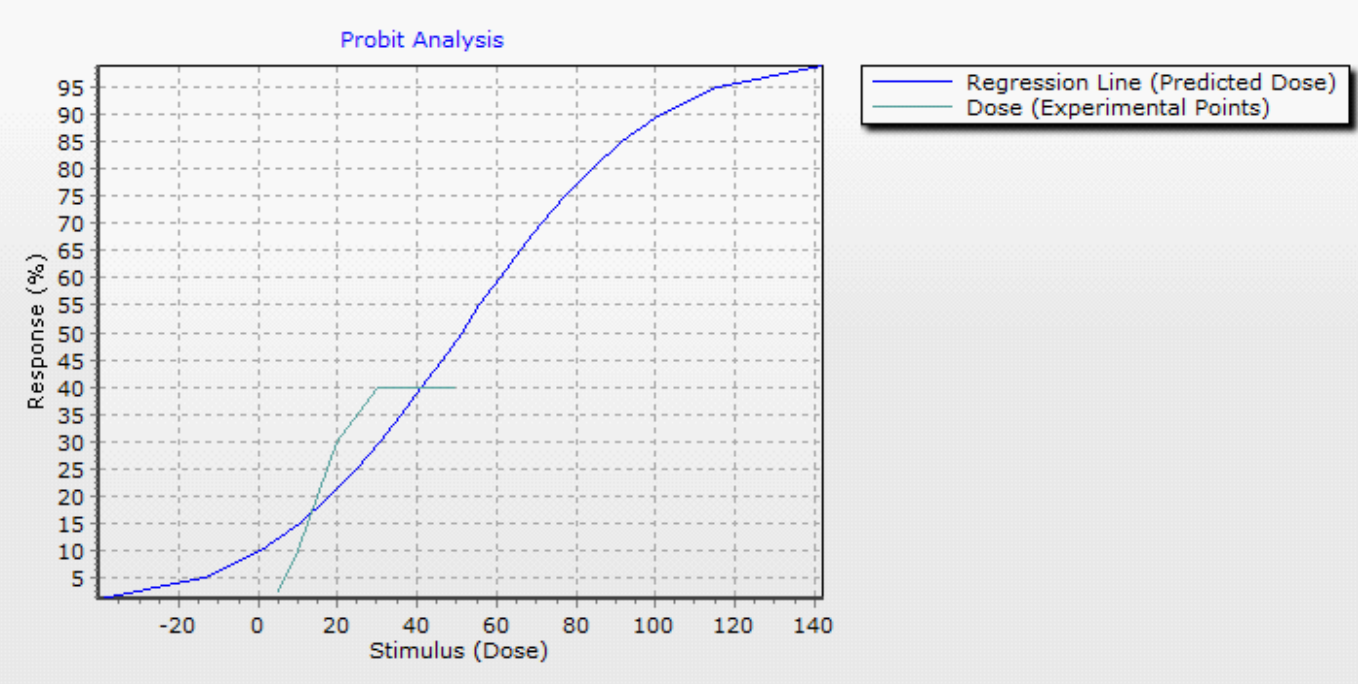

Figure 3: 72 Hours Probit analysis. 
Citation: Praneeth Rahul R, Shirodkar PV, Mani Murali R, Ravindran J, Brahma S, et al. (2013) Response of Penaeid Prawns (Metapanaeus monoceros) to Textile Dye Industrial Effluents (TDIE): An Indicator of Stress. J Environ Anal Toxicol 3: 175. doi:10.4172/2161-0525.1000175

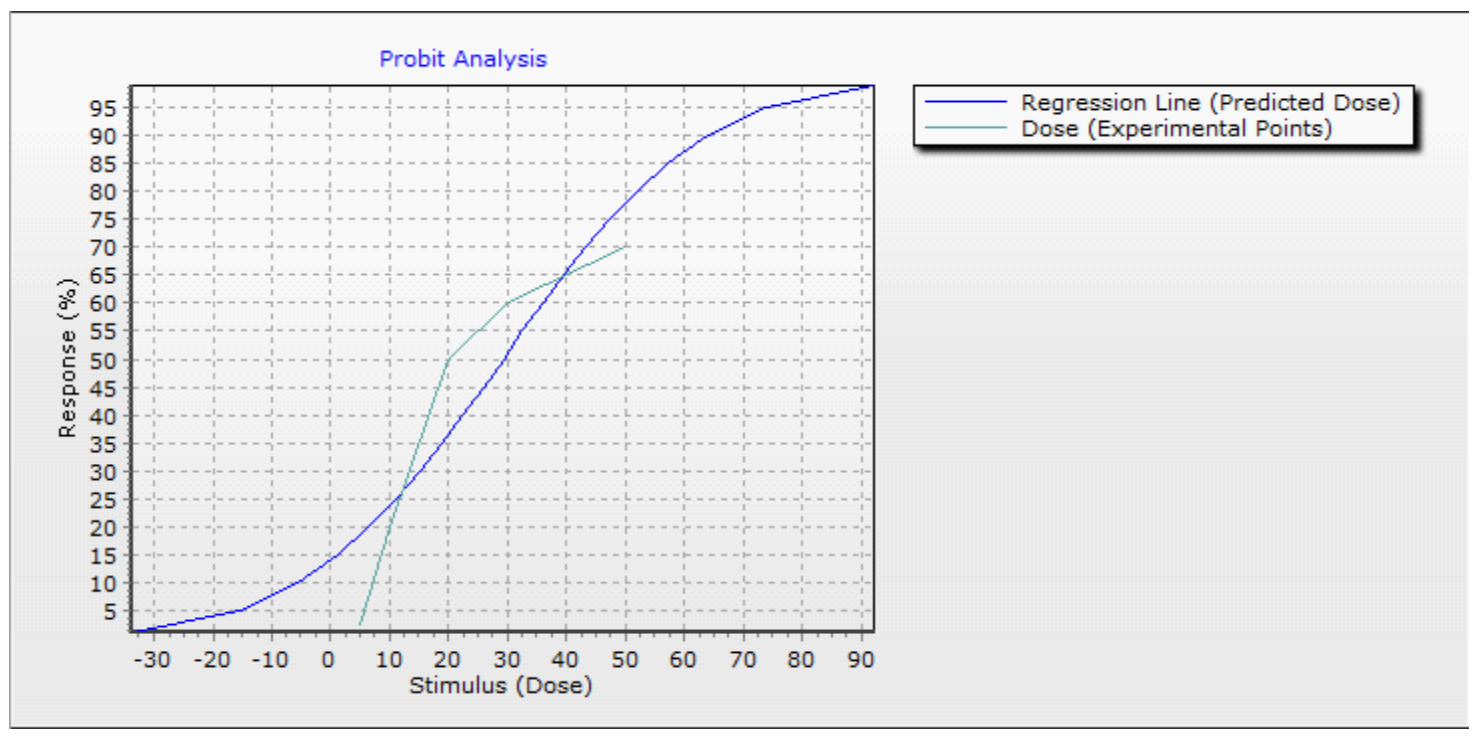

Figure 4: 96 Hours probit analysis.

mixture with a dilution factor of 20 , whereas, zero mortality $(0 \%)$ was observed in effluent mixture with a dilution factor of 200 at $96 \mathrm{hr}$

Earlier studies by Sridevi and Kanmani [6], by taking effluents from other textile dyeing industries in Erode area with a dilution factor of 5 showed high mortality of $100 \%$ and zero mortality $(0 \%)$ at dilution factor of 20. Our results in the present study showed that the response of the penaeid prawns (Metapaeneus monoceros) to RO rejects from the Textile dye industrial effluents (TDIE) are more toxic.

The $\mathrm{LC}_{50}$ for effluent sample at $48 \mathrm{hr}$ exposure period was $120 \mathrm{ppm}$, the upper limit is $159 \mathrm{ppm}$ and the lower limit is $80 \mathrm{ppm}$. The $\mathrm{LC}_{50}$ for $72 \mathrm{~h}$ exposure period was $51 \mathrm{ppm}$, the upper limit is $69 \mathrm{ppm}$ and lower limit is $33 \mathrm{ppm}$. The $\mathrm{LC}_{50}$ for $96 \mathrm{~h}$ exposure period was $29 \mathrm{ppm}$, the upper limit is $41 \mathrm{ppm}$ and the lower limit is $17 \mathrm{ppm}$.

The study shows that the overall toxicity increases when a number of effluents are mixed together. It is therefore concluded that the effluent mixture from 736 textile dying industries in Erode should be thoroughly treated before it is discharged through a common effluent pipe line.

\section{Acknowledgement}

The authors are thankful to the Director, National Institute of Oceanography (CSIR), Goa (India) for providing all the facilities required for this study.

\section{References}

1. Sarathi JN, Karthik R, Logesh S, Rao SK, Vijayanand K (2011) Environmental issues and its impacts associated with textile processing units in Trippur, Tamilnadu. IPCBEE 4.

2. Rana KS, Raizada S (1999) Acute toxicity of tannery and textile dye effluents on a common teleost, Labeo rotia, Histological alterations in liver. J Evn Biology 20: 33-36.

3. Strickland JDH, Parsons TR (1968) Determination of reactive nitrite. In: A Practical Handbook of Seawater Analysis. Fisheries Research Board of Canada, Bulletin 167: 71-75.

4. Grasshoff K, Kremling K, Ehrhardt M (1983) Methods of Seawater Analysis. Wiley-VCH 419.
5. APHA (American Public Health Association) (1989) Standard Methods for the Examination of Waters and Wastewaters, 17th edition American Public Health Association, Washington, DC

6. Sridevi Karpagavalli, Kanmani (2010) Toxicity Evaluation of Ozonation Treated Textile Dyeing Wastewater. IJEP 30: 757-760.

7. Achuthankutty CT, Nair SRS, Krishnakumari L (1993) Growth of juvenile shrimp, Metapenaeus monoceros fed with squid and mussel. Ind J Mar Sci 22: $283-286$

8. Reddy R, Pillai BR, Adhikari S (2006) Bioaccumulation of copper in postlarvae and juveniles of freshwater prawn Macrobrachium rosenbergii (de Man) exposed to sub-lethal levels of copper sulfate. Aquaculture 252: 356-360.

9. Finney DJ (1971) Probit Analysis, third edn. Cambridge University Press London and New York.

10. Russo RC (1985) Ammonia, nitrate and nitrite. In GM Randall, SR Petrocelli, Fundamentals of aquatic toxicology. Hemisphere Publishing, Washington, USA 455-557.

11. Smith VH (1983) Low nitrogen to phosphorus ratios favor dominance by bluegreen algae in lake phytoplankton. Science 221: 669-671.

12. Chen JC, Lei SC (1990) Toxicity of ammonia and nitrite to Penaeus monodon juveniles. J World Aquac Soc 21: 300-306.

13. Chin TS, Chen JC (1987) Acute toxicity of ammonia to larvae of the tiger prawn Penaeus monodon. Aquaculture 66: 247-253.

14. Chen JC, Chin TS (1988) Acute toxicity of nitrite to tiger prawn, Penaeus monodon larvae. Aquaculture 69: 253-262.

15. Chen JC, Lin MN (1991) Lethal and sub-lethal effects of ammonia to Penaeus penicillatus juveniles. Bull Inst Zool Acad Sin 30: 73-80.

16. Cheng SY, Chen JC (1998) Effects of nitrite on the oxygen consumption and ammonia excretion of tiger shrimp Penaeus monodon. J Fish Soc Taiwan 25 209-218.

17. Lewis Jr WM, Morris DP (1986) Toxicity of nitrite to fish: a review. Trans Am Fish Soc 115: 183-195.

18. Boyd CE (1999) Water Quality: An Introduction. The Netherlands: Kluwer Academic Publishers.

19. U.S. Environmental Protection Agency, Office of Water, (1986) Quality Criteria for Water (Gold Book). EPA 440/5-86-001. Washington DC. 